\title{
SILVER/POLYETHYLENE GLYCOL NANOCOMPOSITE THIN FILMS AND ITS BIOLOGICAL APPLICATIONS
}

\author{
Alaa Fahmy*, Adham Al-Zomarawy, Ahmed Z. Sayed, Mohamed A. Ezz El-Arab, Hassan A. \\ Shehata, Ahmed M. Saeed
}

Chemistry Department, Faculty of Science, Al-Azhar University, Nasr City,11884 Cairo, Egypt.

Corresponding author *: Dr. rer. nat. Alaa Fahmy

Email: alaa.fahmy@azhar.edu.eg

Tel. +2 010 / 2121-5388; Fax: +2 02 /26229009;

\begin{abstract}
The synthesis of silver nanoparticles with different sizes and concentrations was carried out using $\mathrm{NaBH}_{4}$ as a reducing agent and polyethylene glycol (PEG) as a stabilizer. The thin films of PEG embedded with Ag nanoparticles (Ag NPs) were deposited by electrospray deposition technique (ESD) and the morphology of subsequent prepared films was studied by AFM. Structure-property relationships of the colloid and subsequent films were discussed in dependence on the concentration of $\mathrm{NaBH}_{4}$. The synthesized Ag/PEG nanocomposite solution was characterized by UV-visible spectroscopy and Transmission electron microscopy (TEM). Chemical composition in the whole and on the surface of films were investigated by Fourier transform infrared (ATR-IR) and X-ray photoelectron microscopy (XPS), respectively. The UVvisible results indicate to the formation of spherical Ag NPs where the absorption peak was observed at wavelengths around $395 \mathrm{~nm}$. TEM images showed the well dispersion of Ag NPs in the PEG matrix with average particle size of $13 \mathrm{~nm}$. Furthermore, the antimicrobial activity of the nanocmposite was studied. The Ag NPs released from the polymer matrix proven to have a significant antimicrobial activity against S. Pneumonia, B. Subtilis, E. Coli, and A. Fumigates.
\end{abstract}

\section{Keywords}

Silver nanoparticle, polyethylene glycol, electrospray deposition, thin films, surface modification

\section{Council for Innovative Research}

Peer Review Research Publishing System

\section{Journal: Journal of Advances in Chemistry}

Vol 11, No. 5

editorjaconline@gmail.com, www.cirjac.com 


\section{INTRODUCTION}

Nanomaterials are differing in physico-chemical and biological properties as compared to their macroscale counterpart of the similar chemical compositions [1]. Therefore, various types of inorganic particles have been used in polymer/inorganic particle nanocomposites preparation including metals (e.g., Al, Fe, Au, and Ag), metal oxides (e.g., $\mathrm{ZnO}, \mathrm{Al}_{2} \mathrm{O}_{3}, \mathrm{CaCO}_{3}$, and $\mathrm{TiO}_{2}$ ), non-metal oxides (e.g., $\mathrm{SiO}_{2}$ ) and others (e.g., $\mathrm{SiC}$ ) [2]. Among silver nanoparticles (Ag-NPs) have received intensive studies in the field of nanotechnology due to their well-known effectiveness in various fields such as biomedical [3], electronic [4], catalytic [5], optical applications [6], photo catalysts [7]. Additionally, nanosilver is the most promising antibacterial agent due to its greater antibacterial effect as compared to bulk silver materials [8].

Various methods were used for silver nanoparticles synthesis, which include chemical reduction [9], electrochemical methods [10], photoinduced reduction [11], and microwave-assisted synthesis [12]. However, nanocomposites are a new class of materials that exhibit enhanced properties [13]. Nanocomposite is made up of inorganic nanoparticles dispersed in organic polymer matrix. It gains typical properties of organic polymers (e.g. elasticity, transparency or specific absorption of light, dielectrically properties) with the advantages of nanoparticles.

Many polymers have been used as NPs stabilizing media such as polyvinyl alcohol [14], polyacrylic acid [15], polyvinylpyrrolidone [16], and Polyethylene glycol [16]. Polymers play an important role in the metal-polymer nanocomposites acting as reducing and/or capping agents and thus prevent particle growth and aggregation. The presence polymer hinders the growth of particles by controlling the nucleation.

On one hand, in situ growth of nanoparticles in a polymer matrix is a simple and efficient method to incorporate inorganic NPs into polymer matrix [17]. Generally, the principles of an in-situ method include:

1. Polymer molecules used as nanoreactors and provide a confined medium for the synthesis (so, controlling particle size and distribution). 2. Polymer molecules stabilize and isolate the generated NPs, thus preventing their aggregation.

On the other hand, preparation of polymer films is limited to a few techniques, such as spin coating, plasma polymerization [18] and chemical vapor deposition. In the last decade, electrospray technique has a great importance for the researches deals with nanoscience and nanotechnology because of its high deposition efficiency and coating of large uniform areas, using equipment of low cost, deposition at atmospheric conditions. Moreover, it is easy to control the film thickness by adjusting voltage and flow rate in this method [19].

In this work, polyethylene glycol/silver nanocomposite successfully prepared by chemical reduction of silver nitrate with respect to different concentrations of sodium borohydride as a strong reducing agent in presence of polyethylene glycol (PEG) as a mild reducing and/or stabilizing agent. PEG is frequently used in the synthesis of Ag nanoparticles because of its wide range of molecular weights, low toxicity, chain flexibility and biocompatibility properties. Besides, PEG was able to act both as reducing agent and stabilizer. Longer polymer chain of PEG exhibits a higher reducing activity and provides higher stability in forming Ag NPs was proposed [20].

A combination of surface and bulk characterization methods were used to investigate the relationship between size and stability of Ag NPs colloids as well as thin solid films prepared by the electrospray deposition system (ESD). Since its implementation as a required process for drinking water treatment, disinfection has greatly reduced the risk associated with waterborne bacterial diseases. Chlorination is the most common method of disinfection; but one risk involved with chlorination is contact with natural organic matter, carcinogenic compounds such as trihalomethanes and haloacetic acids can be formed. A second problem associated with chlorination as a means of water disinfection is due to multi-drug resistant bacterial species [21]. While some alternative technologies (e.g. UV-irradiation, ozonation) have been extensively researched and even employed in some water treatment facilities, problems have still been acknowledged with these newer disinfection techniques (e.g. minimal-level residual). Thus, further studies in this field are of great importance for overall human and environmental health. Silver nanoparticles (Ag-NPs) can be anchored on a polymer for water disinfection. Upon anchoring Ag ions, particular bacterial strains were selected as indicator microorganisms; two of which were gram-positive and two gram-negative [22,23].

\section{EXPERIMENTAL SECTION}

\subsection{Materials}

PEG 4000 obtained from (Alfa Aesar. USA). $\mathrm{AgNO}_{3}$ (assay 99.85\%) and $\mathrm{NaBH}_{4}$ (assay 99\%) were received from (Acrosorganics New Jersey, USA). Methanol (HPLC grade, assay 99\%)) was obtained from (Macron fine chemicals, Norway). All of the used chemicals are of analytical grade and used without any further purification.

\subsection{Synthesis of Ag/PEG Nanocomposite}

PEG $(2.5 \mathrm{~g})$ was dissolved in methanol $(25 \mathrm{~mL})$, then, $\mathrm{AgNO}_{3}(0.004 \mathrm{~g})$ was added to the PEG solution and the reaction was stirred for $1 \mathrm{~h}$. at room temperature $\left(25^{\circ} \mathrm{C}\right)$ in dark place. The solution of $\mathrm{NaBH}_{4}(0.001 \mathrm{M})$ in deionized water (DDW) was added to the reaction mixture in different volumes $(0.1,0.2,0.25$ and $0.3 \mathrm{~mL})$. The mixture colorless was turning to brown color at the first drop of $\mathrm{NaBH}_{4}$ added as an indication of the formation of Ag-NPs. The stirring was continued at room temperature in the dark place to avoid any photochemical reaction for another 2 hours to ensure the completion of reduction process. The samples were designated as $\mathrm{R} 1, \mathrm{R} 2, \mathrm{R} 3$ and $\mathrm{R} 4$ for $0.1,0.2,0.25$ and $0.3 \mathrm{~mL}^{\circ} \mathrm{NaBH}_{4}$, respectively. 


\subsection{Fabrication of Ag/PEG Nanocomposite Films Using Electrospray Deposition Technique (ESD)}

The fabrication of Ag/PEG nanocomposite films using electrospray deposition system is shown in Fig. (1). The system consists of a high voltage power supply (12KV) with two terminal electrodes, the positive electrode is connected to the stainless steel needle (nozzle) and the other electrode (ground) is connected to a sheet of aluminum. A silicon wafer is placed over the aluminum sheet to act as conductive substrate for the deposition of thin films. The distance between the tip of the needle and the Si-wafer was $5 \mathrm{~cm}$. The nanocomposite solutions are injected through a burette ended with stainless steel needle at flow rate $3.33 \mu \mathrm{L} / \mathrm{min}$, the deposition time was 20 minutes. The parameters used in the deposition process represent the optimum conditions for the fabrication of a homogeneous and pinhole free thin film.

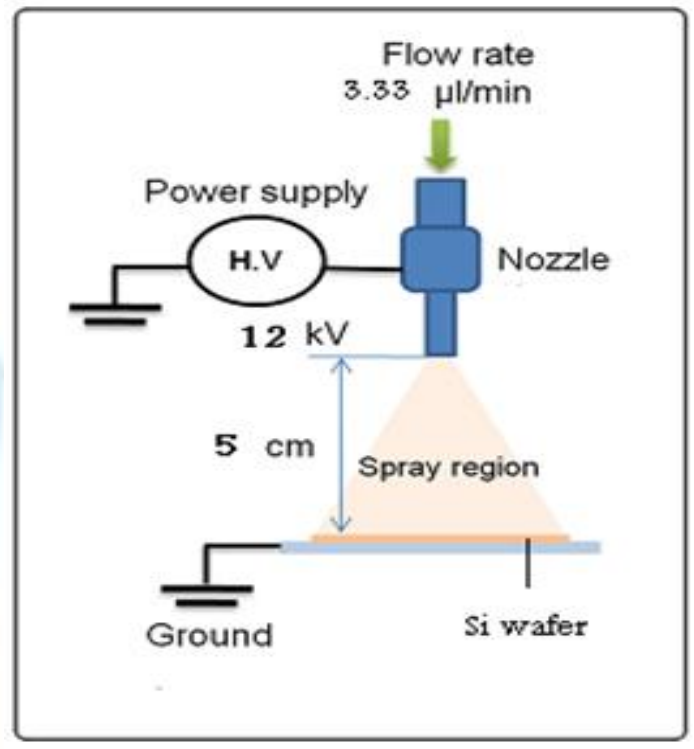

Figure 1. Schematic description of the (ESI) process parameters

\subsection{Antimicrobial Activity}

The antimicrobial activity of the nanocomposite solution against a wide range of an environmental and clinically pathogenic microorganism was evaluated using the diffusion agar technique. Samples under investigation were individually tested against a panel of Gram positive such as S. Pneumonia, B. Subilis, Gram negative as $P$. Aeruginosa, E. Coli as pathogenic bacteria, A. Fumigates, C.Albicans as fungi.

Antibacterial tests were carried out using agar well diffusion method, with $100 \mathrm{ml}$ suspension containing $1 \times 10^{8}$ colony forming units CFU/ml pathological tested bacteria, $1 \times 10^{4}$ spore $/ \mathrm{ml}$ fungi spread on nutrient agar and malt extract agar (MA), respectively [24]. After the media had cooled and solidified wells (6mm in diameter) were made in the solidified agar and loaded with $100 \mu$ l of testing sample.

The inoculated plates were then incubated for $24 \mathrm{~h}$ at $37^{\circ} \mathrm{C}$ for bacteria and $48 \mathrm{~h}$ at $28^{\circ} \mathrm{C}$ for fungi. Ampicillin $(50 \mu \mathrm{g} / \mathrm{mL})$, Genatmicin $(50 \mu \mathrm{g} / \mathrm{mL})$ and Amphotericin B $(50 \mu \mathrm{g} / \mathrm{mL})$ were used as blank for Gram positive bacteria, Gram negative bacteria and fungi respectively. After incubation, antimicrobial activity was evaluated by measuring the zone of inhibition against the test organisms and compared with that of the standard. Antimicrobial activity was expressed as inhibition diameter zone in millimeters $(\mathrm{mm})$ (average zone of inhibition). The experiment was carried out in triplicate and the data was expressed as mean \pm standard deviation (SD).

The antimicrobial activity of $\mathrm{Ag} / \mathrm{PEG}$ nanocomposite thin film which prepared by ESD method was done according to the

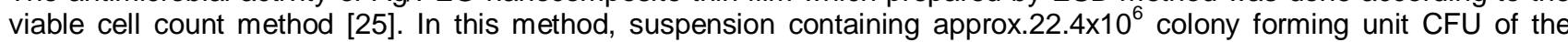
bacterial species E.coli was treated overnight with control as well as Ag/PEG nanocomposite thin film. These suspensions were then cultured on nutrient agar plates and incubated for $24 \mathrm{~h}$. The colonies in bacterial species were then counted and the reduction percentage of bacterial growth in the presence of $\mathrm{Ag} / \mathrm{PEG}$ nanocomposite thin film compared to the control.

\section{RESULTS AND DISSCUSION}

\subsection{Synthesis of [Ag /PEG] Nanocomposites}

The most frequently methods which used to prepare dispersion of silver nanoparticles embedded in polymer matrices involve the entrapment of silver ions by polymer chains. Polymers act as surface capping agent, followed by reduction of silver ions with common reducing agents.

This method presents two advantages compared to the simple mixing of the two components and the polymerization in the presence of presynthesized silver nanoparticles. First, the template role of the host macromolecular chains in the 
synthesis of nanoparticles was improved the dispersion of nanoparticles inside the polymeric matrix and also the aggregation process was prevented. Second, the polymer chains were played an important role in the reduction of the metal ions into nanoparticles as well as the size of nanoparticles with narrow size distribution and well defined shape. PEG was employed as a stabilizer and polymeric media for the reduction of $\mathrm{AgNO}_{3}$ using $\mathrm{NaBH}_{4}$. This method produced ultra small and well dispersed silver nanoparticles. The synthesis of Ag NPs capped with PEG is shown schematically in Scheme 1.

It was proposed that the colloidal stabilization of Ag-PEG composite occurs due to the presence of van der Waals forces between the oxygen negatively charged groups present in the molecular structure of the PEG and the positively charged groups that surround the surface of inert Ag NPs [26].

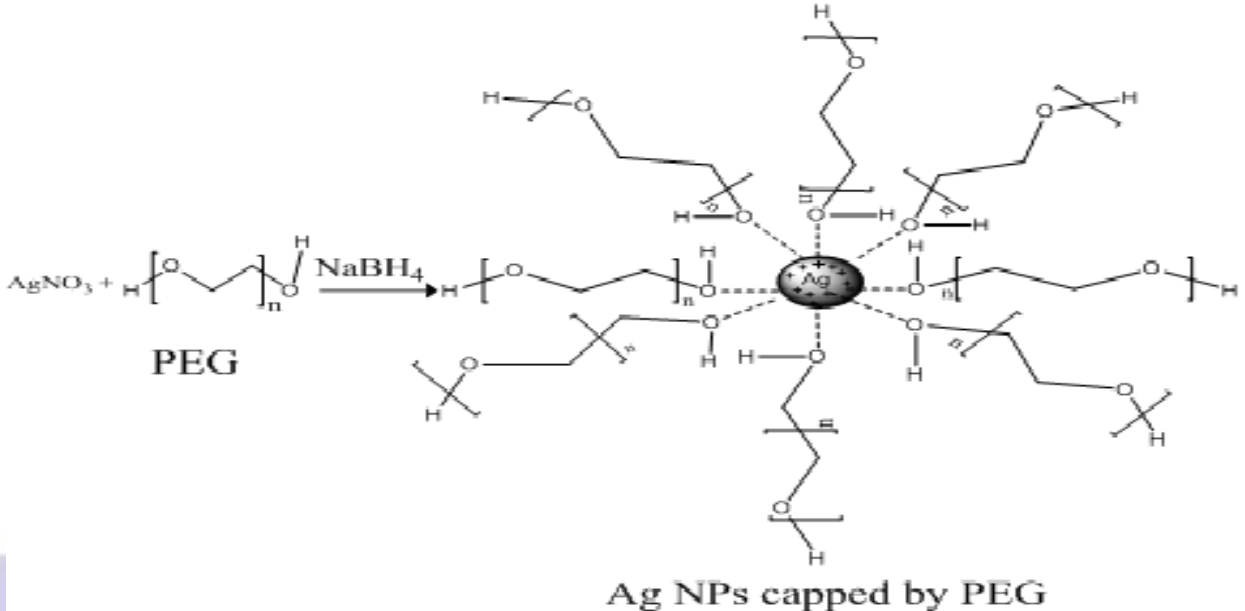

Scheme1. The interactions between hydroxyl groups on PEG with the surface of positive charge of silver nanoparticles [Ag-PEG] [27]

The Ag/PEG nanocomposite was characterized using a combination of surface and bulk characterization methods such as FTIR, XPS, AFM, TEM and UV-vis spectroscopy.

\subsection{UV-vis Spectroscopy}

UV-visible spectroscopy is one of the popular characterization techniques to detect the nanoparticles formation and its properties. UV-visible measurements were evaluated using Lambda 25 UV/Vis spectrometer, PerkinElmer, Inc. Once the $\mathrm{NaBH}_{4}$ was added to $\mathrm{AgNO}_{3}$ and PEG mixture, the colorless mixture turns to brown color giving an indication on the formation of $\mathrm{Ag}-\mathrm{NPs}$. The intensity of the color increases gradually with increasing the concentration (volume) of the $\mathrm{NaBH}_{4}$. The brown solutions are stable for three months indicating the effective capping of the PEG.

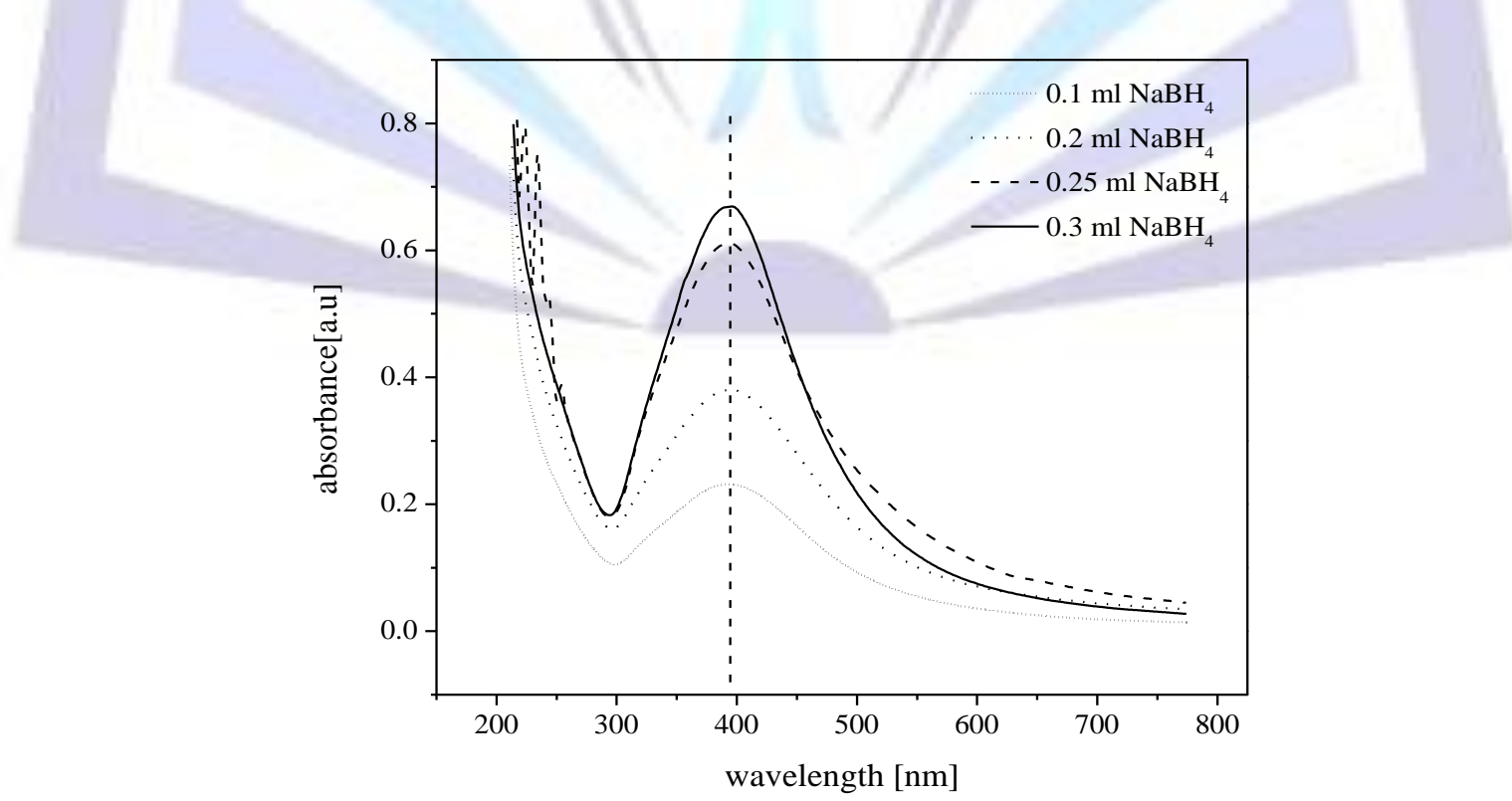

Figure 2.UV-vis spectrum of Ag-NPs prepared in the PEG solution with different concentrations of the reducing agent 
The absorption peak was observed at ca. $395 \mathrm{~nm}$ characteristic for Ag-NPs in the UV-vis region due to the surface plasmon resonance (SPR) of silver nanoparticles [28]. It is well recognized that the absorbance of Ag NPs depends mainly upon the size and shape. First observation, the absorption peaks appeared around $395 \mathrm{~nm}$ and the existence of a single SPR peaks for each sample indicates the successful synthesis of spherical Ag-NPs. This is in agreement with the previous results and predictions for spherical nanoparticles with a mean particle size below $20 \mathrm{~nm}[29,30]$. The SPR absorption band was enhanced and sharpened gradually with increasing the amount of $\mathrm{NaBH}_{4}$ (Fig. 2). At lower concentrations of the reducing agent, the SPR band was broad. The reason is due to the formation of particles with a broad size distribution [31]. Therefore, the size and shape of the particles were investigated using transmission electron microscopy.

\subsection{Transmission Electron Microscopy (TEM)}
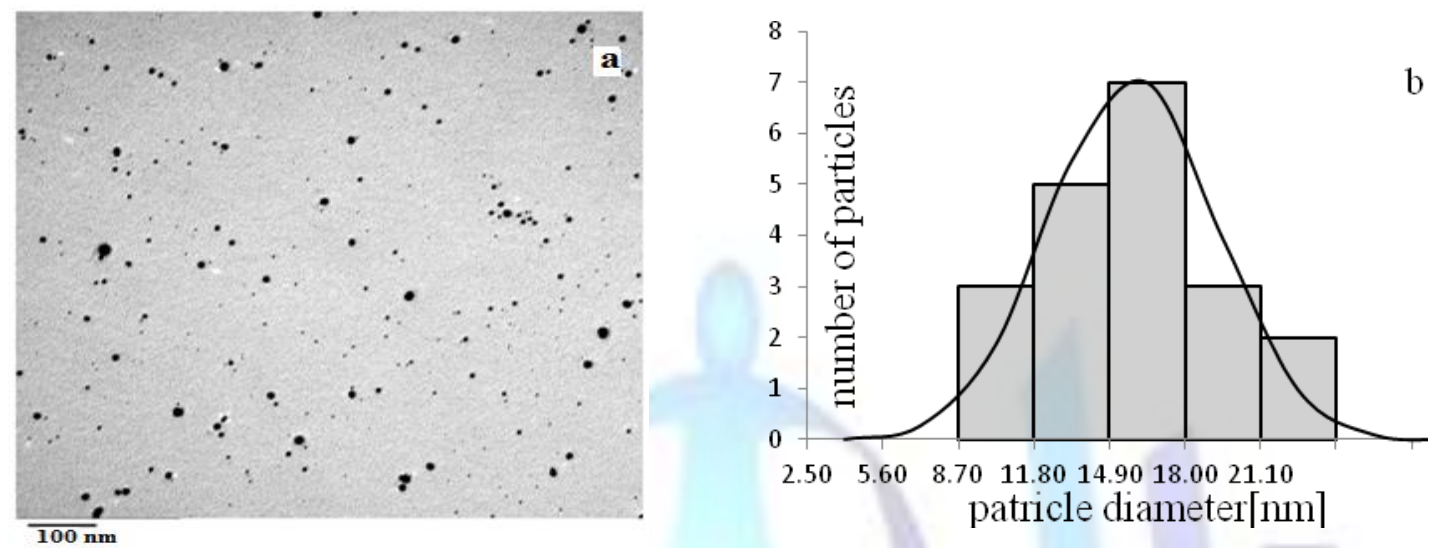

Figure 3.TEM image (a) and particle size distribution histogram (b) for the sample prepared by reduction with 0.3 $\mathrm{mL} \mathrm{NaBH}_{4}$

The size and shape of $\mathrm{Ag}$ nanoparticles were investigated by transmission electron microscopy (TEM) (JEOL JEM10x10 Electron Microscope). A few drops of Ag/PEG nanocomposite solution were dropped onto a TEM carbon coated grid, and the residue was removed by a filter paper under the TEM grid. The TEM image of the sample R4 as an example (Fig. 3a) proves that Ag nanoparticles are well dispersed with spherical or roughly spherical shape. The average size of the Ag-NPs was determined from the peak position of the Gaussian fitting and equal to $12.7 \mathrm{~nm}$ (Fig. 3b) with a standard deviation $3.4 \mathrm{~nm}$.

However, a number of mono-dispersed spherical Ag NPs were homogeneously distributed throughout the whole image field of the sample R1 (Fig 4a) but the aggregation of the nanoparticles was observed. In this sample, the average size of Ag nanoparticles is ca. $15.7 \mathrm{~nm}$ with a standard deviation $3.2 \mathrm{~nm}$ (Fig 4b).
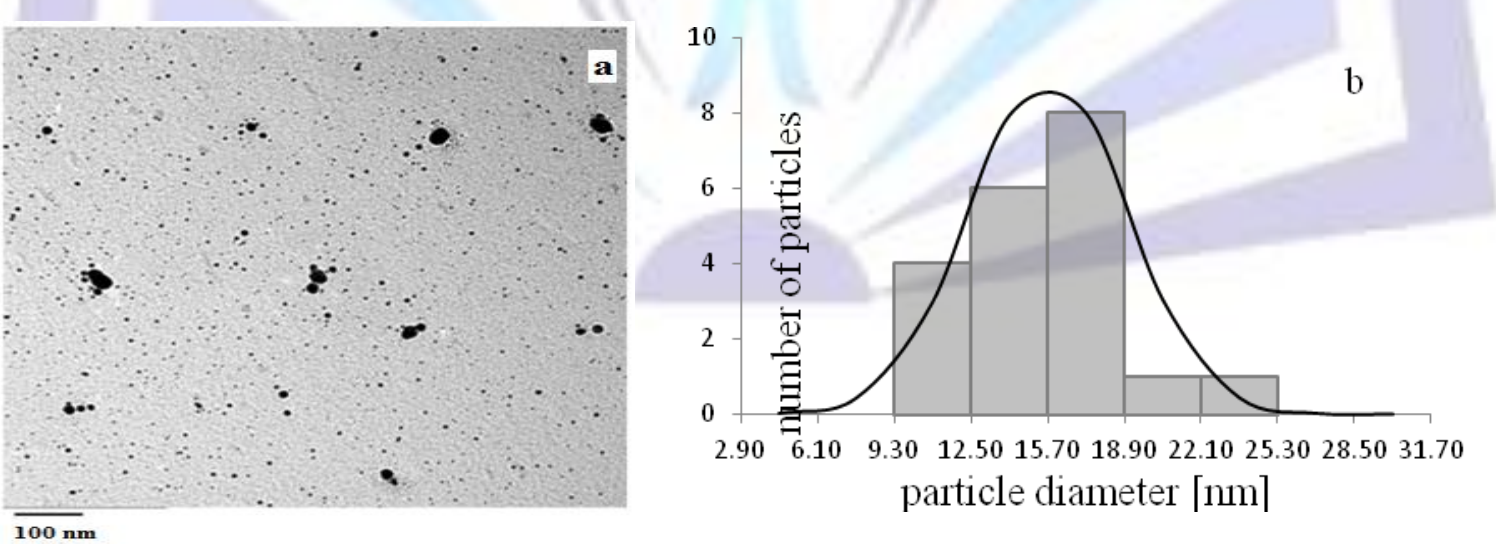

Figure 4. TEM image (a) and particle size distribution histogram (b) for the sample prepared with $0.1 \mathrm{~mL} \mathrm{NaBH}_{4}$

From the results of TEM analysis, it can be noted that, as the concentration of reducing agent increases, the size of $\mathrm{Ag}$ NPs decreases and agreeing well with the shape of SPR band in the UV-vis spectra.

\subsection{Attenuated Total Reflection-Infrared (ATR- IR)}

FTIR spectra were characterized in the wavenumber range from 4000 to $500 \mathrm{~cm}^{-1}$ accumulating 64 scans with a resolution of $4 \mathrm{~cm}^{-1}$ using a Nicolet Nexus 8700 FTIR spectrometer (Nicolet, USA) equipped with the appropriate ATR 
accessory (Diamond Golden Gate, one reflection). All spectra were subjected to the diamond ATR and baseline correction.

The stracture of Ag/PEG nanocomposites were confirmed on the basis of IR spectra data. The Figure (5) represents IR spectra for Ag/PEG nanocomposites were prepared with different amount of the reducing agent in comparison to the PEG as blank.

For the spectrum of PEG, the band appeared at $3460 \mathrm{~cm}^{-1}$ related to the $\mathrm{O}-\mathrm{H}$ stretching vibrations associated with $\mathrm{v}$ $\left(\mathrm{CH}_{3}{ }^{\text {as }}\right)$ at $\sim 2940 \mathrm{~cm}^{-1}, \mathrm{v}\left(\mathrm{CH}_{2}{ }^{\text {as }}\right)$ at $\sim 2920 \mathrm{~cm}^{-1}, v\left(\mathrm{CH}_{3}^{\mathrm{s}}\right)$ at $2890 \mathrm{~cm}^{-1}$, and the $\mathrm{v}\left(\mathrm{CH}_{2}^{\mathrm{s}}\right)$ vibrations at $2880 \mathrm{~cm}^{-1}$ are observed together with the corresponding $\vee(\mathrm{C}-\mathrm{O})$ vibration at $\sim 1062 \mathrm{~cm}^{-1}$ [32]. Whereas, the bands at 1463 and 1340 $\mathrm{cm}^{-1}$ for $\mathrm{C}-\mathrm{H}$ bending vibrations. Additionally, the absorption bands at 1279 and $1105 \mathrm{~cm}^{-1}$ were due to the stretching vibrations of the alcoholic $\mathrm{O}-\mathrm{H}$ and $\mathrm{C}-\mathrm{O}-\mathrm{C}$ ether linkage. C-OH stretching frequency was observed at $1062 \mathrm{~cm}^{-1}$ and $\mathrm{C}-\mathrm{C}$ skeletal vibration frequencies were seen at 957 and $840 \mathrm{~cm}^{-1}$ [33]. The FT-IR measurements reveal that, the intensity of the $\mathrm{C}-\mathrm{O}$ bond that observed at $\sim 1114 \mathrm{~cm}^{-1}$ in the nanocopmposites was increased as the concentration of $\mathrm{NaBH}_{4}$ increased. Furthermore, the intensity of the $\mathrm{OH}$ band at $\sim 3460 \mathrm{~cm}^{-1}$ was increased in the samples R1, R4, R2 and R3 compared to the pure PEG. This may be attributed to the traces of the solvent (Methanol) in the samples.

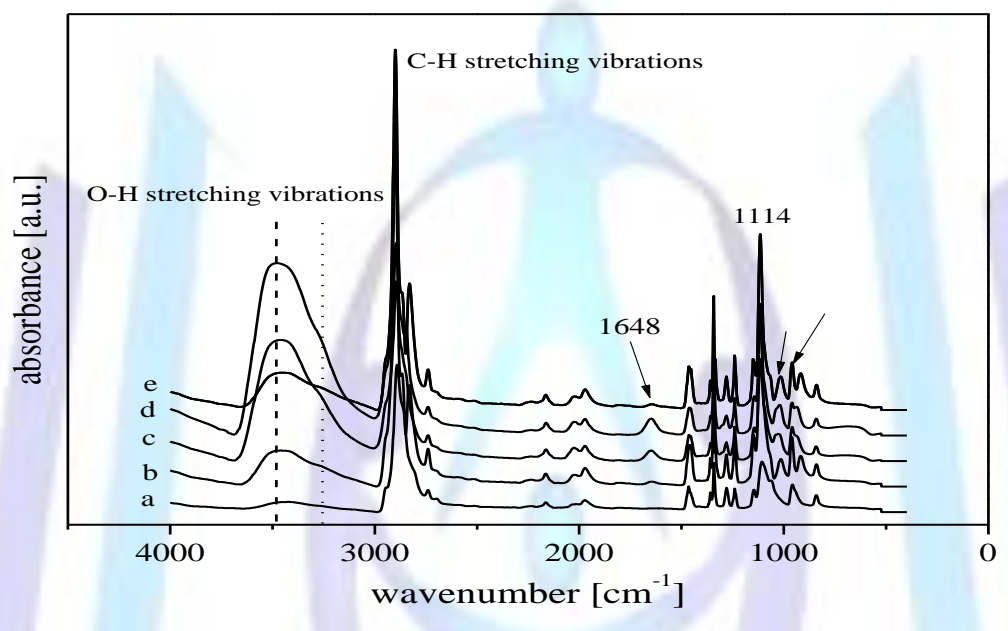

Figure 5. FT-IR spectra of PEG (a) and PEG/Ag nanocomposites prepared with 0.1 (b), 0.2 (c), 0.25 (d) and $0.3 \mathrm{~mL}$ (e) $\mathrm{NaBH}_{4}$

The new peak at $1648 \mathrm{~cm}^{-1}$ is appeared in the composite samples. This band corresponds to the carbonyl groups formed as a result of the interaction of $\mathrm{Ag}$ ions with $\mathrm{C}-\mathrm{O}-\mathrm{H}$ and subsequent reduction of metal ions to form metal nanoparticles.

On the other hand, the wavenumber range of the $-\mathrm{OH}$ vibration from $3700 \mathrm{~cm}^{-1}$ to $3100 \mathrm{~cm}^{-1}$ reveals that this band is quite complex and consists at least of two different contributions. The main component at $\sim 3460 \mathrm{~cm}^{-1}$ is attributed to the hydroxyl stretching vibration $(\mathrm{C}-\mathrm{OH})$ of PEG. The second contribution with a shoulder at $\sim 3300 \mathrm{~cm}^{-1}$ is related to the vibration of another structural unit. This band is due to hydrogen bonded $\mathrm{H}-\mathrm{OH}$ or $\mathrm{OH}$ groups from a few amount of the solvent which may be remained in the sample.

\subsection{X-ray Photoelectron Spectroscopy (XPS)}

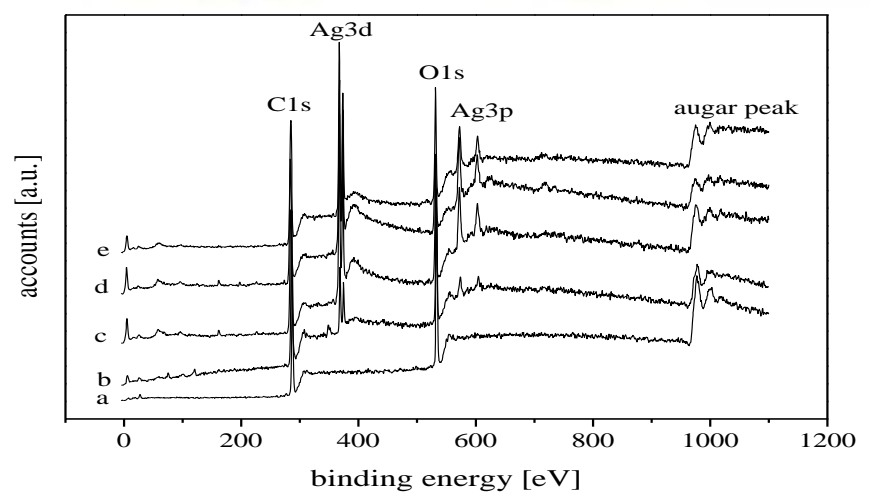

Figure 6. XPS spectrum of PEG (a) and PEG/Ag nanocomposites prepared with 0.1 (b), 0.2 (c) 0.25 (d) and $0.3 \mathrm{~mL}$ (e) $\mathrm{NaBH}_{4}$ 
The surface composition was investigated using X-ray photoelectron spectroscopy (XPS) by analyzing the C1s, O1s and $\mathrm{Ag}$ 3d peaks. The spectrometer of SAGE 150 (Specs, Berlin, Germany) was used and equipped with a hemispherical analyzer Phoibos 100 MCD-5 and utilized a non-monochromatic MgKa radiation with $11 \mathrm{kV}$ and $220 \mathrm{~W}$ settings at a pressure of ca. $1 \times 10^{-7} \mathrm{Pascal}$ in the analysis chamber. The experiments were performed to elucidate the chemical state of $\mathrm{Ag}$ particles. Fig. (6) shows the XPS survey spectrum of $\mathrm{Ag} / \mathrm{PEG}$ nanocoposites prepared with different concentrations of $\mathrm{NaBH}_{4}$ and compared with $\mathrm{PEG}$ as blank. The full spectrum indicates the presence of the silver $(\mathrm{Ag})$, oxygen $(\mathrm{O})$ and carbon (C) atoms. The XPS peaks at binding energies (BE) of 285 and $532 \mathrm{eV}$ which are attributed to $\mathrm{C} 1 \mathrm{~s}$ and $\mathrm{O}$ 1s, respectively.

Additionally, the XPS spectra of Ag/PEG nanocoposites samples clearly showed the appearance of Ag3d peaks in the range 364-378 eV. The silver ion shows an anomalous positive shift in the B.E. upon reduction to silver metal, that is the Ag3d peaks shift to the higher B.E. values for reduction form of silver metal [34]. The Ag3d-XPS peak envelop was deconvoluted into two component peaks at ca. $368.8 \mathrm{eV}$ and $367.2 \mathrm{eV}$, which correspond to the two different states of silver, namely metallic silver $\left(\mathrm{Ag}^{0}\right)$ and silver ion $\left(\mathrm{Ag}^{+}\right)$, respectively $[35,36]$. The analysis of the decomposed $\mathrm{Ag} 3 \mathrm{~d}$ peak provided the composition of $\mathrm{PEG}-\mathrm{AgNO}_{3}$ sample, as shown in Fig. 7.

It is noted that the binding energies for $\mathrm{Ag}$ electron configurations of $3 \mathrm{~d} 5 / 2$ and $3 \mathrm{~d} 3 / 2$ were $368.8 \mathrm{eV}$ and $374.6 \mathrm{eV}$, respectively, with a difference of $(5.8 \mathrm{eV})$, and comparable to the standard $\mathrm{Ag}$ 3d binding energies $(3 \mathrm{~d} 5 / 2=368.3 \mathrm{eV}$, $3 \mathrm{~d} 3 / 2=374.3 \mathrm{eV}, \Delta \mathrm{E}=6.0 \mathrm{eV}$ ) [37]. It can be seen that the doublet separation of $3 \mathrm{~d}(3 \mathrm{~d} 5 / 2$ and $3 \mathrm{~d} 3 / 2)$ photoemission of the metallic $\mathrm{Ag}$ occurred and shows higher (BE) than that of $\mathrm{Ag}$ bulk metal $(3 \mathrm{~d} 5 / 2=368.3 \mathrm{eV}, 3 \mathrm{~d} 3 / 2=374.3 \mathrm{eV})$. This shift in the (BE) of nanostructured materials might be attributed to three main effects which include: charging [38], size [39], and chemical (bonding) effects [35].

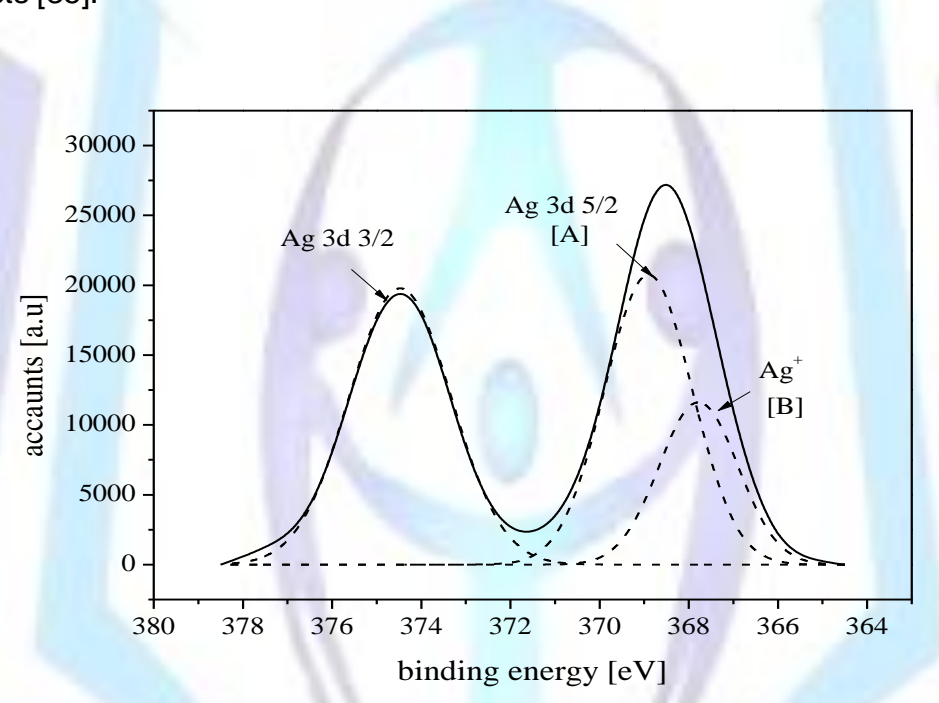

Figure 7. High-resolution XPS spectra of Ag3d. The solid line represents the experimental data. The dashed line is a fit of a sum of Gauss function to the data

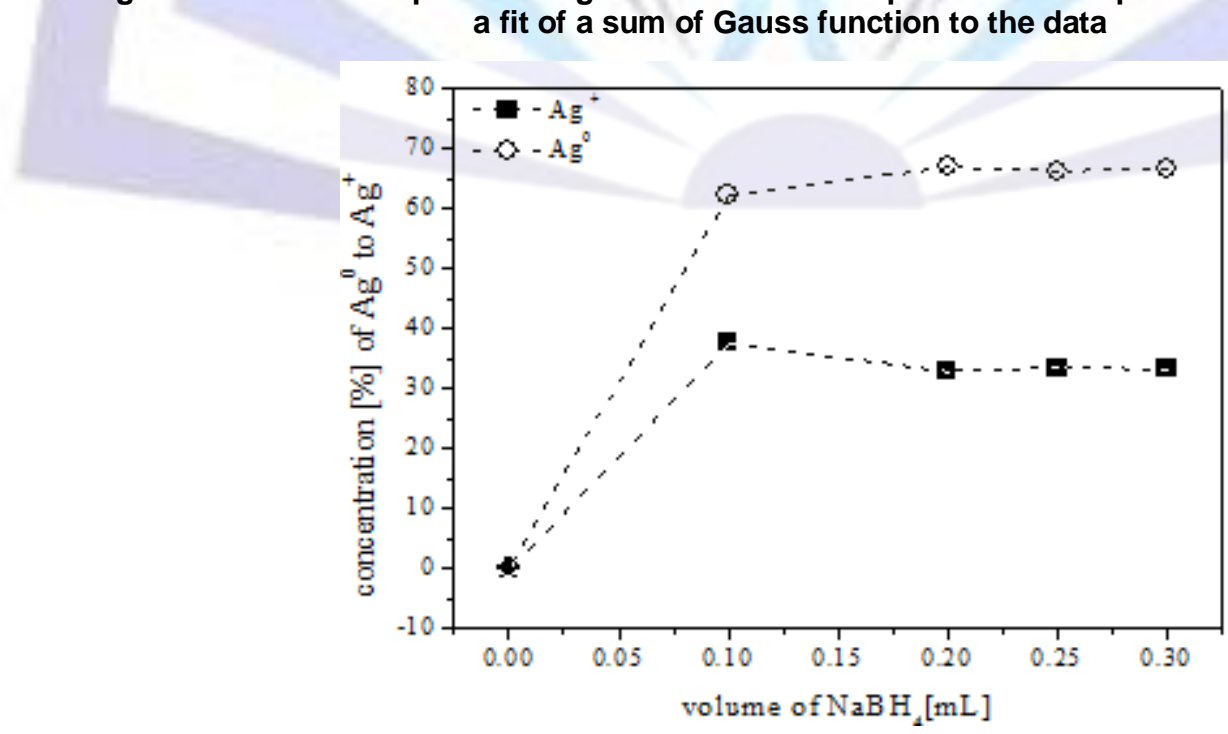

Figure 8. The ratio of $\mathrm{Ag} \mathrm{NPs}$ and $\mathrm{Ag}$ ions in the Ag/PEG nanocomposite samples vs. the amount of $\mathrm{NaBH}_{4}$ in comparison to PEG blank sample 
On the other hand notes that, as the concentration of $\mathrm{NaBH}_{4}$ increases, the concentration of $\mathrm{Ag}$ metal $\left(\mathrm{Ag}^{\circ}\right)$ increases as well, and subsequent, the concentration of $\mathrm{Ag}$ ions $\left(\mathrm{Ag}^{+}\right)$decreases as shows in Fig. (8).

\subsection{Atomic Force Microscopy (AFM)}

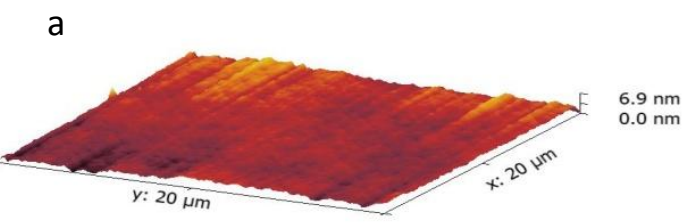

b

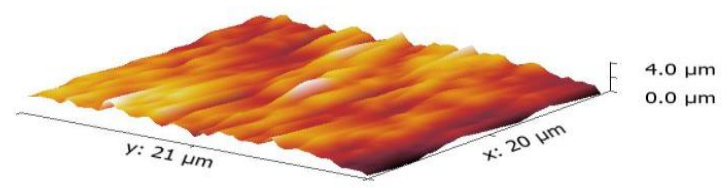

C

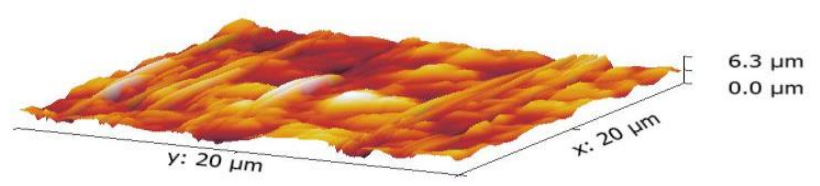

Figure 9. AFM 3D images of Si-wafers (a) ESD deposition of: pure PEG (b) and Ag/PEG nanocompsite (R3) (c) onto Si-wafer

The surface topography and morphology of the PEG and Ag/PEG nanocomposite thin films was investigated using atomic force microscopy (AFM) model Autoprobe cp-research head manufactured by Thermomicroscope, the number of data points was $256^{\star} 256$, and the scan rate was $1 \mathrm{~Hz}$. AFM was operated in contact mode using a nonconductive silicon nitride probe, manufactured by Bruker model MLCT-MT-A using proscan 1.8 software for controlling the scan parameters and IP 2.1software for image analysis. Each sample was scratched up to the bottom and then the thickness was measured as height of this scratch using AFM and it was equal to $3 \mu \mathrm{m}$. A homogenous and smooth surface with PEG deposited thin films by ESD method was obtained.

Fig. 9a shows the 3D images of the Si-wafer. The Si-wafer had an average roughness of $0.3 \mathrm{~nm}$ while for PEG deposited onto Si wafer samples by ESD technique have of $0.453 \mu \mathrm{m}$ (Fig. 9b). The root mean square (rms) roughness was calculated for R3 sample and it was found to be $0.681 \mu \mathrm{m}$. According to the results, the roughness of the PEG thin film was largely higher than the silicon substrate. Also, the roughness of the sample R3 thin film revealed that nanoparticles significantly changed the morphology of the film surface. These increases might be related to more nucleation sites produced by nanoparticles or agglomeration of nanoparticles. [40]

\subsection{Biological Activity Evaluation}

Antimicrobial activity of Ag/PEG nanocomposite was evaluated using the diffusion agar technique. The mean zones of inhibition in $\mathrm{mm} \pm$ standard deviation beyond well diameter $(6 \mathrm{~mm})$ produced on a range of environmental and clinical pathogenic microorganisms compared with the standard were shown in Table1. 
On one hand, a gradual increase in the zone of inhibition diameter was observed as the concentrations of $\mathrm{NaBH}_{4}$ increased (Table 1). As discussed before, the concentrations of Ag-NPs were increased with growth the $\mathrm{NaBH}_{4}$ as well as the size of the Ag-NPs was decreased.

In the antifungal tests, it was noted that all of the samples have no activity toward (Candida albicans) while in the case of (Aspergillus fumigates) the samples showed promising results. The minimum zone of inhibition was obtained for R1, whereas it was the maximum zone of inhibition for R4. R2 and R3 have zones of inhibition of $(15.6 \pm 0.44 \mathrm{~mm})$ and $(18.1 \pm$ $0.58 \mathrm{~mm})$, respectively. For the antibacterial test all of samples have no activity toward (Pseudomonas aeruginosa) where a positive effect on the other two types of bacteria (gram positive and negative) with varying activities (Table 1).

The R1 sample has a minimum zone of inhibition while R4 sample like that observed for antifungal test has the maximum zone of inhibition for both gram positive bacteria (Streptococcus Pneumonia and Bacillus subtillis) and gram negative bacteria (E.coli).

Table 1. Biological activity of Ag/PEG nanocomposite (100 $\mu \mathrm{L}$ doses) and commercial antibiotics (standard) (100 $\mu L$ doses) in agar diffusion method, NA = no activity.

\begin{tabular}{|c|c|c|c|c|c|}
\hline \multirow{2}{*}{$\begin{array}{c}\text { Tested } \\
\text { microorganisms }\end{array}$} & \multicolumn{5}{|c|}{ Mean zone of inhibition(mm) } \\
\hline & R1 & R2 & R3 & R4 & standard \\
\hline Fungi & & & & & AmphotericinB \\
\hline A.fumigates & $12.6 \pm 0.58$ & $15.6 \pm 0.44$ & $18.1 \pm 0.58$ & $18.6 \pm 0.36$ & $23.7 \pm 0.1$ \\
\hline C. albicans & $\mathrm{NA}$ & NA & NA & NA & $25.4 \pm 0.1$ \\
\hline \multicolumn{2}{|c|}{ Gram positive bacteria } & & & & Ampicillin \\
\hline S.Pneumonia & $14.6 \pm 0.43$ & $16.9 \pm 0.44$ & $19.2 \pm 0.44$ & $19.6 \pm 0.63$ & $23.8 \pm 0.2$ \\
\hline B. subtillis & $16.2 \pm 0.53$ & $19.3 \pm 0.25$ & $19.3 \pm 0.63$ & $20.0 \pm 0.32$ & $32.4 \pm 0.3$ \\
\hline \multicolumn{2}{|c|}{ Gram negative bacteria } & & & & Gentamicin \\
\hline P.aeruginosa & NA & NA & NA & NA & $17.3 \pm 0.1$ \\
\hline E.coli & $13.7 \pm 0.25$ & $14.9 \pm 0.44$ & $15.4 \pm 0.58$ & $15.9 \pm 0.46$ & $19.9 \pm 0.3$ \\
\hline
\end{tabular}

Therefore, it can be concluded that the antifungal and antibacterial effect were increased as the size of the Ag NPs was decreased and its concentration increased.

On the other hand, the antimicrobial activity of Ag/PEG nanocomposite thin film prepared by ESD was investigated according to viable count method using E.coli as model bacteria. The total bacterial count of the tested sample and reduction percent $(\mathrm{R} \%)$ of the sample $(\mathrm{R} 4)$ against E.coli are recorded in Table 2. The reduction percent of bacterial growth in the presence of Ag/PEG nanocomposite film was estimated using the following formula [41]:

$$
R(\%)=[(A-B) / A] \times 100
$$

where $A$ and $B$ are the numbers of $C F U / m L$ of bacteria in the liquid culture in the presence of control and $A g / P E G$ nanocomposite thin film, respectively.

Table 2. Antibacterial activity of R4 sample as a thin film prepared by ESD technique

\begin{tabular}{|c|c|c|c|}
\hline \multirow{2}{*}{$\begin{array}{c}\text { Tested } \\
\text { microorganism }\end{array}$} & $\mathbf{3}$ & \multicolumn{3}{|c|}{ Count CFU } \\
\cline { 2 - 4 } & $\mathbf{R 4}$ & Control & $\begin{array}{c}\text { Reduction percent } \\
\text { (R)\% }\end{array}$ \\
\hline E.coli & $16.4 \times 10^{3}$ & $22.4 \times 10^{6}$ & 99.93 \\
\hline
\end{tabular}

The film exhibited high reduction percentage of the E.Coli concentration (99.93\%) compared to the control one. It can be clearly seen that the growth of the bacteria was significantly hindered by the nanocomposite thin film. According to these results, the Ag/PEG nanocomposite solution and thin film exhibit excellent antimicrobial activity was concluded.

\subsubsection{Action of Silver Nanoparticles Mechanism on Microbes}

Several mechanisms have been proposed to explain the inhibitory effect of Ag NPs on bacteria. It was assumed that the high affinity of silver towards sulfur and phosphorus is the key element of the antimicrobial effect. Ag NPs have the ability to anchor to the bacterial cell wall and subsequently penetrate it, thereby causing structural changes in the cell membrane like the permeability of the cell membrane and death of the cell. There is formation of 'pits' on the cell surface, and there is an accumulation of the nanoparticles on the cell surface [42]. 
The formation of free radicals by the silver nanoparticles may be considered to be another mechanism by which the cells die. These free radicals have the ability to damage the cell membrane and make it porous which can ultimately lead to cell death [43]. It has also been proposed that silver ions [44] can interact with the thiol groups of many vital enzymes and inactivate them [45]. The bacterial cells in contact with silver take in silver ions, which inhibit several functions in the cell and damage the cells. The cells are majorly made up of sulfur (Ag NPs can react with sulfur-containing amino acids inside or outside the cell membrane) and phosphorus which are soft bases and silver is a soft acid [46], the action of these nanoparticles on the cell takes place and subsequently lead to cell death.

The antifungal action of Ag NPs can be suggested as follows: Ag NPs attach to the cell membrane and penetrate in the fungi then produce a site with little molecular weight in center of fungi, and then Ag NPs attach to respiratory sequence and finally cell division stop leads to cell death. Moreover, Ag NPs release silver ion in fungal cell which increase the antifungal function as a result [47]. Additionally, during Ag NPs exposure, there are significant changes to Fungal cell membranes, which are recognized by the formation of "pits" on their surfaces, and finally, result in the formation of pores and cell death [48].

\section{CONCLUSION}

Thin films of PEG embedded with silver nanoparticles were prepared using electrospray deposition technique (ESD). The effect of variation of the reducing agent concentration on the size of the Ag nanoparticles also was studied, and showed that the size of silver nanoparticle decreased with increasing the concentration of the $\mathrm{NaBH}_{4}$. The Ag-NPs in the polymeric matrix distributed well with an average particle size of around $13 \mathrm{~nm}$ as revealed by TEM image. The formation of uniform and well-shaped nanoparticles was accounted as a result of using proper protecting agent (PEG).

The antimicrobial activity of the prepared Ag/PEG nanocomposite solution showed that the Ag nanoparticles exhibit higher antimicrobial activity when its size was decreased and its concentration was increased. However, results indicated that $\mathrm{Ag} / \mathrm{PEG}$ nanocomposite is selective in its antibacterial action. The thin film of Ag/PEG nanocomposite prepared by elecrospray deposition technique (ESD) showed that the thin film exhibit excellent antimicrobial activity. This demonstrates that the composite films might be employed as environmental friendly and antimicrobial surface in the biomedical applications. Therefore, it could be useful for drinking water treatment, disinfection.

\section{REFERENCES}

[1] Heidarpour F., Ghani W.A.W.A.K., Ahmadun F.R., Sobri S., Zargar M., Mozafari M.R., Nano silver-coated polypropylene water filter: I. Manufacture by electron beam gun using a modified balzers 760 machine Dig. J. Nanomater. Biostruct. 5, (2010), 787-796.

[2] Kango S., Kalia S., Celli A., Njuguna J., Habibi Y., Kumara R., Surface modification of inorganic nanoparticles for development of organic-inorganic nanocomposites-A review, Progress in Polymer Science, 38, (2013), $1232-1261$.

[3] Cao X.L., Cheng C., Ma Y.L., Zhao C.S., Preparation of silver nanoparticles with Antimicrobial activities and the researches of their biocompatibilities, J. Mater. Sci. Mater. Med. 21, (2010), 2861-2868.

[4] Mohan Y.M., Lee K.J., Premkumar T., Geckeler K.E., Hydrogel networks as nanoreactors: A novel approach to silver nanoparticles for antibacterial applications. Polymer 48, (2007), 158-164.

[5] Feng X., Qi X., Li J., Yang L.W., Qiu M.C., Yin J.J., Lu F., Zhong J.X. Preparation, structure and photo-catalytic performances of hybrid $\mathrm{Bi}_{2} \mathrm{SiO}_{5}$ modified Si nanowire arrays Preparation. Appl. Surf. Sci. 257, (2011), 5571-5575.

[6] Hayward R.C., Saville D.A., Aksay I.A., Electrophoretic assembly of colloidal crystals with optically tunable micropatterns. Nature.404, (2000), 56-59.

[7] Zhang Y., Zhang K., Ma H., Electrochemical DNA biosensor based on silver Nanoparticles/poly (3-(3-pyridyl) acrylic acid)/carbon nanotubes modified electrode. Anal.Biochem. 387, (2009), 13-19.

[8] Rai M.K., Deshmukh S.D., Ingle A.P., Gade A.K., Silver nanoparticles: the powerful nanoweapon against multidrug resistant bacteria. J. Appl. Microbiol. 112, (2012), 841-852.

[9] Khanna P.K., Kulkarni D., Beri R.K., Synthesis and characterization of myristic acid capped silver nanoparticles. J. Nanopart Res. 10(2008), 1059-1062.

[10] Yin B.S., Ma H.Y., Wang S.Y., Chen S.H., Electrochemical Synthesis of Silver Nanoparticles under Protection of Poly (N-vinylpyrrolidone) J. Phys. Chem. B.107, (2003), 8898-8904.

[11] Jin R.C., Cao Y.W., Mirkin C.A., Photoinduced Conversion of Silver Nanospheres to Nanoprisms. Science. 294, (2001), 1901-1903.

[12] Yamamoto T., Yin H., Wada Y.J., Morphology-Control in Microwave-Assisted Synthesis of Silver Particles in Aqueous Solutions. Chem. Soc. Jpn 77, (2004), 757-761.

[13] Jeon I.Y., Baek J.B., Nanocomposites derived from polymers and inorganic nanoparticles. Materials 3, (2010), 36543674. 
[14] Gaddy G.A., Korchev A.S., McLain J.L., Slaten B.L., Steigerwalt E.S., Light induced formation of silver particles and clusters in cross linked PVA/PAA films. Mills .J. Phys. Chem. B 108, (2004), 14850-14857.

[15] Wang T.C., Rubner M.F., Cohen R.E., Polyelectrolyte multilayer nanoreactors for preparing silver nanoparticle composites: controlling metal concentration and nanoparticle size, Langmuir. 18, (2002), 3370-3375.

[16] Luo C.C., Zhang Y.H., Zeng X.W., Zeng Y.W., Wang Y.G., The role of polyethylene glycol in the formation of silver nanoparticles. J Colloid Interf Sci.288, (2005), 444-448.

[17] Fusheng P.,Cheng Q., Jia H., Jiang Z., Facile approach to polymer-inorganic nanocomposite membrane through abiomineralization-inspired process. J. Membrane Sci. 357 (2010), 171-177.

[18] Fahmy A., Mix R., Schönhals A., Friedrich J., Surface and Bulk Structure of Thin Spin Coated and PlasmaPolymerized Polystyrene Films. Plasma Chem Plasma Process 32, (2012), 767-780.

[19] Park C.H., Lee J., Electrosprayed polymer particles: Effect of the solvent properties. J. Appl Polym. Sci. 114, (2009), 430-437.

[20] Luo C.C., Zhang Y.H., Wang Y.G., (Palladium nanoparticles in polyethylene glycol): the efficient and recyclable catalyst for Heck reaction. J Mol Catal A-Chem. 229, (2005), 7-12.

[21] Lalley J., Dionysiou D.D., Varma R.S., Shankara S., Yang D.J., Nadagouda M.N., Silver-based antibacterial surfaces for drinking water disinfection - An overview, Current Opinion in Chemical Engineering. 3, (2014), $25-29$.

[22] Gangadharan D., Harshvardan K., Gnanasekar G., Dixit D., Popat K.M., Anand P.S., Polymeric microspheres containing silver nanoparticles as a bactericidal agent for water disinfection. Water Res. 44, (2010), 5481-5487.

[23] Mthombenia N.H., Mpenyana-Monyatsib L., Onyangoa M.S., Momba M.N.B., Breakthrough analysis for water disinfection using silver nanoparticles coated resin beads in fixed-bed column. J Hazard Mater. 217-218, (2012), 133-140.

[24] Scott A.C., Laboratory control of antimicrobial therapy. In: Collee JG et al. eds. Practical Medical Microbiology, $13^{\text {th }}$ edn. Edinburgh:Churchill Livingstone, (1989),161-181.

[25] Thomas V., Murali M.Y., Sreedhar B., Bajpai S.K., Fabrication, Characterization of Chitosan/Nanosilver Film and Its Potential Antibacterial Application, J. Biomaterials Science, Part A: Polymer Edition, 20, (2009), 2129-2144.

[26] Dallas P., Sharma V.K., Zboril R., Silver polymeric nanocomposites as advanced antimicrobial agents: Classification, synthetic paths, applications, and perspectives. Adv. Colloid Interface Sci. 166, (2011), 119-135.

[27] Raveendran P., Fu J., Wallen S.L., Completely "green" synthesis and stabilization of metal nanopartcieles. J. Am. Chem. Soc. 125, (2003),13940-13941.

[28] Liz-Marzán L.M., Tailoring Surface Plasmons through the Morphology and Assembly of Metal Nanoparticles. Langmuir, 22, (2006), 32-41.

[29] Mock J.J., Barbic M., Smith D.R., Schultz D.A., Schultz S. Shape effects in plasmon resonance of individual colloidal silver nanoparticles. J Chem. Phys. 116, (2002), 6755-6760.

[30] Slistan-Grijalvaa A., Herrera-Urbinab R., Rivas-Silvac J.F., valos-Borjad M.A, Castillo'n-Barrazad F.F., PosadaAmarillas A., Assessment of growth of silver nanoparticles synthesizedfrom an ethylene glycol-silver nitratepolyvinylpyrrolidone solution. Physica E, 25, (2005) 438-448.

[31] Vidhu V.K., Aromal S.A., Philip D., Green synthesis of silver nanoparticles using Macrotyloma uniform. Spectrochimica Acta Part A, 83, (2011), 392-397.

[32] Fahmy A., Schönhals A., Friedrich J., Reaction of Water with (Radicals in) Plasma Polymerized Allyl Alcohol (and Formation of OH-Rich Polymer Layers). J. Phys. Chem. B. 117, (2013), 10603-10611.

[33] Saravanan L., Subramanian S., Surface chemical studies on the competitive adsorption of poly (ethylene glycol) and ammoniumpoly(methacrylate)onto zirconia. Colloids Surf. A: Physicochem. Eng. Aspects 252, (2005), 175-185.

[34] Weaver J.F., Hoflund G.B., Surface characterization study of the thermal-decomposition of AgO. J. Phys. Chem. 98, (1994), 8519-8524.

[35] He S., Yao J.N., Xie S.S., Pang S.J., Gao H.J., Investigation of passivated silver nanoparticles. Chem Phys Lett. 343 , (2001), 28-32.

[36] Krylova G.V., Gnatyuk Y.I., Smirnova N.P., Eremenko A.M., Gunko V.M., Ag nanoparticles deposited onto silica, titania, and zirconia mesoporous films synthesized by sol-gel template method Journal of sol-gel science and technology. 50, (2009), 216-228.

[37] Shin H.S., Choi H.C., Jung Y., Kim S.B., Song H.J., Shin H.J., Chemical and size effects of nanocomposites of silver and polyvinyl pyrrolidone determined by X-ray photoemission spectroscopy. Chemical Physics Letters. 383, (2004), 418422. 
[38] Wertheim G.K., DiCenzo S.B., Buchanan D.N.E., Noble and transition-metal clusters: The d bands of silver and palladium. Phys. Rev. B. 33, (1986), 5384-5390.

[39] Paszti Z., Peto G., Horvath Z.E., Karacs A., Guczi L.. Elecronic structure of Ag nanoparticles deposited in Si (100). Solid State Commun. 107, (1998), 329-333.

[40] Upadhyay V.S., Dubey S.K., Singh A., Tripathi S., Structural, Optical and Morphological Properties of $\mathrm{PVA} \mathrm{Fe}_{2} \mathrm{O}_{3}$ Nanocomposite Thin Films. IJCPS. 3, (2014), 43-48.

[41] Kumar V., Jolivalt C., Pulpytel J., Jafari R., Arefi-Khonsari F., Development of silver nanoparticle loaded antibacterial polymer mesh using plasma polymerization process. J Biomed Mater Res Part A, 101A, (2013), 1121-1132.

[42] Sondi I., Salopek-Sondi B., Silver nanoparticles as antimicrobial agent: a case study on E. coli as a model for Gramnegative bacteria. J. Colloid Interface Sci. 275, (2004), 177-182.

[43] Kim J.S., Kuk E., Yu K., Kim J.H., Park S.J., Lee H.J., Kim S.H., Park Y.K., Park Y.H.,Hwang C.-Y., Kim Y.K., Lee Y.S., Jeong D.H., Cho M.H., Antimicrobial effects of silver nanoparticles. Nanomedicine 3, (2007), 95-101.

[44] Feng Q., Wu J., Chen G., Cui F., Kim T., Kim J., A mechanistic study of the antibacterial effect of silver ions on Escherichia coli and Staphylococcus aureus. J Biomed Mater Res. 52, (2008), 662-668.

[45] Matsumura Y., Yoshikata K., Kunisaki S., Tsuchido T., Mode of bacterial action of silver zeolite and its comparison with that of silver nitrate. Appl. Environ. Microbiol.69, (2003), 4278-4281.

[46] Morones J.R., Elechiguerra J.L., Camacho A., Holt K., Kouri J.B., Ramirez J.T., Yacaman M.J., The bactericidal effect of silver nanoparticles. Nanotechnology, 16, (2005), 2346-2353.

[47] Alt V., Bechert T., Steinrucke P., Wagener M., Seidel P., Dingeldein E., Domann E., Schnettler R., An in vitro assessment of the antibacterial properties and cytotoxicity of nanoparticulate silver bone cement. Biomaterials, 25, (2004), 4383-4391.

[48] Nasrollahi A., Pourshamsian K., Mansourkiaee P., Antifungal activity of silver nanoparticles on some of fungi. Int. J. Nano. Dim. 1, (2011), 233-239.

\section{Coresponding author Dr. Alaa Fahmy}

Alaa Fahmy was born and educated in Menofia, Egypt. He obtained his B.Sc. in 2001 and M.Sc. in 2005 in Physical Chemistry from Faculty of Science, Al-Azhar University, Cairo, Egypt. He was obtained his PhD. (natural Chemistry) in 2011 from institute of Polymer Engineering and Polymer Physics, Department of Materials Science and Technology, Technical University Berlin, Germany. He was granted three Post doctoral followships in 2012 and 2014 at BAM Bundesanstalt für Materialforschung und -prüfung, Berlin, Germany and 2013 at Université du Maine, Institut des Molécules et Matériaux du Mans, Le Mans, France. He had REHAU Preis Technik 2011 at Bayreuth University, Germany and nominated for ADOLF-MARTENS-PREIS 2012, Germany. Currently, Dr. Fahmy is working as Assistant Professor at Al-Azhar University, Faculty of Science, Chemistry Department,11884 Cairo, Egypt. 